\title{
SPIRIT 2013 Bildirisi: Klinik Deneyler İçin Standart Protokol Maddelerinin Tanımlanması $\infty$
}

\author{
An-Wen Chan ${ }^{1}$, Jennifer M. Tetzlaff 2, Douglas G. Altman ${ }^{3}$, Andreas Laupacis ${ }^{4}$, Peter C. \\ Gøtzsche ${ }^{5}$, Karmela Krlez a-Jeric' ${ }^{6}$, Asbjørn Hro'bjartsson ${ }^{5}$, Howard Mann7, Kay Dickersin ${ }^{8}$, Jesse \\ A. Berlin ${ }^{9}$, Caroline J. Dore'10, Wendy R. Parulekar ${ }^{11}$, William S.M. Summerskill' ${ }^{12}$, Trish Groves ${ }^{13}$, \\ Kenneth F. Schulz ${ }^{14}$, Harold C. Sox ${ }^{15}$, Frank W. Rockhold ${ }^{16}$, Drummond Rennie ${ }^{17}$, and David \\ Moher ${ }^{18}$
}

\section{Çevirenler \\ Belgin AKIN ${ }^{1}$, Deniz KOÇOĞLU-TANYER ${ }^{2}$}

\section{Öz}

Klinik deney protokolü deneyin planlanması, yürütülmesi, raporlanması ve değerlendirilmesinde temel bir dayanak olarak hizmet eder. Ancak deney protokolleri ve mevcut protokol rehberleri, içerik ve kalite yönünden oldukça fazla çeşitlilik göstermektedir. Bu makale klinik deney protokolünün asgari içeriği için bir rehber olan SPIRIT 2013'ün (Standard Protocol Items: Recommendations for Interventional Trials-Standart Protokol Maddeleri: Girişimsel Deneyler için Öneriler) sistematik olarak geliştirilmesini ve kapsamını tanımlamaktadır. 33-maddelik SPIRIT kontrol listesi tüm klinik deney protokollerine uygulanabilir ve şekilden ziyade içeriğe odaklanır. Kontrol listesi, tüm planlananların tarif edilmesini önerir; bir deneyin nasıl tasarlanacağını ya da yürütüleceğini içermez. SPIRIT önerileri, anahtar içerik için rehberlik sağlayarak, yüksek kaliteli protokol taslağı hazırlanmasını kolaylaştırmayı hedefler. SPIRIT'e bağı ı kalmak aynı zamanda araştırmacılar, deney katılımcıları, hastalar, sponsorlar, ödenek sağlayanlar, araştırma etik komiteleri ya da kurumsal hakem kurulları, hakemler, dergiler, deney kayıt merkezi, politikacılar, düzenleyiciler ve diğer anahtar paydaşlar için deney protokolünün şeffaflı̆ı̆ıı ve bütünlüğünü artırır.

Anahtar kelimeler: Deneysel araştırmalar, raporlama, SPIRIT

\begin{abstract}
ABSTARCT
SPIRIT 2013 Statement: Defining Standard Protocol Items for Clinical Trials

The protocol of a clinical trial serves as the foundation for study planning, conduct, reporting, and appraisal. However, trial protocols and existing protocol guidelines vary greatly in content and quality. This article describes the systematic development and scope of SPIRIT (Standard Protocol Items: Recommendations for Interventional Trials) 2013, a guideline for the minimum content of a clinical trial protocol. The 33-item SPIRIT checklist applies to protocols for all clinical trials and focuses on content rather than format. The checklist recommends a full description of what is planned; it does not prescribe how to design or conduct a trial. By providing guidance for key content, the SPIRIT recommendations aim to facilitate the drafting of high-quality protocols. Adherence to SPIRIT would also enhance the transparency and completeness of trial protocols for the benefit of investigators, trial participants, patients, sponsors, funders, research ethics committees or institutional review boards, peer reviewers, journals, trial registries, policymakers, regulators, and other key stakeholders. Keywords: Experimental studies, reporting, SPIRIT
\end{abstract}

${ }^{1}$ Prof.Dr., Lokman Hekim Üniversitesi, Sağlık Bilimleri Fakültesi, Halk Sağlığı Hemşireliği Anabilim Dalı, Ankara, Türkiye, E-mail: akin.belgin@gmail.com ORCıD: 00000002-8094-4110

${ }^{2}$ Doç.Dr., Selçuk Üniversitesi, Hemşirelik Fakültesi, Halk Sağlığı Hemşireliği Anabilim Dalı, Konya, Türkiye Tel:0332 223 0788, E-mail: deniizkocoglu@gmail.com ORCID: 0000-0001-9496-8749

Geliş Tarihi: 16 Eylül 2020, Kabul Tarihi: 03 Ocak 2021

Atıf/Citation: Chan AW, Tetzlaff JM, Altman DG, Laupacis A, Gøtzsche, PC, Krleža-Jeric' K ve ark. SPIRIT 2013 Bildirisi: Klinik Deneyler İçin Standart Protokol Maddelerinin Tanımlanması (Çev: Akın B, Koçoğlu-Tanyer D). Hacettepe Üniversitesi Hemşirelik Fakültesi Dergisi 2021; 8(1):117-127. DOI: 10.31125/hunhemsire.908072 


\section{Giriş}

Bir klinik deney protokolü, etik onay alınmasından araştırma sonuçlarının yaygınlaştırmasına kadar olan sürecin tüm planlamalarını detaylandırarak çalışmanın planlanması, yürütülmesi, yorumlanması, gözetimi ve dış değerlendirilmesinde anahtar rol oynar. İyi yazılmış bir protokol; deney başlamadan önce bilimsel, etik ve güvenlik konularının uygunluğunun; deney yürütülürken gösterilen tutarlılık ve titizliğin; deney tamamlandıktan sonra ise deneyin yürütülmesi ve sonuçların bütününün incelenmesinin uygun bir şekilde değerlendirilmesini kolaylaştırır. Protokollerin önemi dergi editörleri1-6, akran değerlendiriciler (hakemler) ${ }^{7-10}$, araştırmacılar ${ }^{11-15}$ ve toplum savunucuları tarafından vurgulanmaktadır ${ }^{16}$.

Protokollerin bu merkezi rolüne rağmen, bir sistematik derleme, protokol içeriği için mevcut rehberlerin kapsam ve önerilerinde büyük çeşitlilik olduğunu, rehberlerin nasıl geliştirildiğinin nadiren tanımlandığını ve geniş paydaş katılımına ya da önerilerini destekleyecek deneysel kanıtlara ender olarak atıfta bulunulduğunu ortaya koymuştur ${ }^{17}$. Bu sınırlılıklar protokollerin kalitesinin iyileştirilmesine neden ihtiyaç duyulduğunu kısmen de olsa açıklayabilir. Pek çok randomize deney protokolü, birincil çıktılarını (deneylerin \%25'inde yetersiz) ${ }^{18,19}$, deney ve kontrol grubuna atama yöntemlerini (\%54-79'unda yetersiz) 20,21 , körlemenin kullanılmasını (\% 9-34' ünde yetersiz) $)^{21,22}$ ters etkileri raporlama yöntemlerini (\%41'inde yetersiz) ${ }^{23}$, örneklem hesabının bileşenlerini (\%4 -40'ında yetersiz $)^{21-24}$, veri analiz planlarını $\left(\begin{array}{llll}\% & 20 & -77^{\prime} & \text { sinde }\end{array}\right.$ yetersiz) ${ }^{21}, 24-26$, yayın politikalarını (\%7'sinde yetersiz) ${ }^{27}$ ve sponsor ve araştırmacıların çalışma tasarımı ya da verilere erişimdeki rollerini (\%89-100'ünde yetersiz) ${ }^{28,29}$ yeterince tanımlamamaktadır. Protokollerin yetersiz/eksik olmasının altında yatan asıl problemler/sorunlar, önlenebilir protokol düzeltmelerine, deneylerin kalitesiz yürütülmesine ve yayınlanmasında yetersiz/ uygunsuz raporlamaya yol açabilirir ${ }^{15,30}$.

Protokol içeriği ve rehberlerindeki bu boşluklara karşı, Biz 2007'de SPIRIT (Standard Protocol Items: Recommendations for Interventional Trials- Standart Protokol Maddeleri: Girişimsel Deneyler için Öneriler) girişimini başlattık. Bu uluslararası proje, deney protokollerinde bulunması gereken asgari maddeler (dizisi) için kanıta dayalı öneriler üreterek deney protokollerinin eksiksizliğini geliştirmeyi hedeflemektedir. SPIRIT 2013 bildirisi 33-maddelik bir kontrol listesi (Tablo 1) ve diyagram (Şekil 1) içermektedir. ilgili açıklayıcı metinde (SPIRIT 2013-Açıklama ve Ayrıntılandırma) ${ }^{31}$ gerçek protokollerin rehberliği ve model örnekleri ile kontrol listesinin her bir maddesi gerekçeler ve destekleyen kanıtlar ile detaylandırılmıştır.

\section{SPIRIT 2013 Bildirisinin Geliştirilmesi}

SPIRIT 2013 bildirisi, rolleri birbiriyle örtüşmeyen (birbirinden farklı) deney araştırmacıları $(n=30)$, sağlık bakım profesyonelleri $(n=31)$, yöntem bilimciler $(n=34)$, istatistikçiler $(n=16)$, deney koordinatörleri $(n=14)$, dergi editörleri $(n=15)$ ve araştırma etiği temsilcileri $(n=17)$, sanayi ve sanayi dışı kaynak sağlayıcılar $(n=7)$, ve
SPIRIT 2013 Bildirisi

SPIRIT 2013 Statement

düzenleyici kurullar kural koyucular $(n=3)$ olmak üzere 115 anahtar paydaşın görüşlerine başvurularak geniş bir katılım ile geliştirilmiştir. Daha sonra detaylandırıldığı gibi SPIRIT rehberi, 2 sistematik derleme, bir resmi Delphi uzlaşım süreci, 2 yüz yüze uzlaşım toplantısı ve pilot denemeden yararlanılarak geliştirilmiştir ${ }^{32}$.

SPIRIT kontrol listesi pek çok tekrarlarla gelişmiştir. Süreç mevcut protokol rehberlerinin bir sistematik derlemesinden oluşturulan 59 maddelik bir ön-kontrol listesi ile başlamıştır ${ }^{17}$. 2007' de, düşük $(n=1)$, orta $(n=6)$ ve yüksek gelirli $(n=10) 17$ ülkeden toplam 96 uzman panelist bu başlangıç kontrol listesini e-posta ile 3 kez tekrarlayan Delphi uzlaşım anket turu ile rafine etmiştir ${ }^{33}$. Panelistler her bir maddeyi 1'den (önemli değil) 10'a kadar (çok önemli) bir ölçekte derecelendirmiş, yeni maddeler önermiş ve sonraki turlar için yorumlarda bulunmuşlardır. Son etapta medyan puanı 8 ve üzerinde olan maddeler dahil edilirken 5 ya da daha düşük puanlılar çıkarılmıştır. 58 arasında puanlanan maddeler uzlaşım toplantısında tartışılmak üzere tutulmuştur.

Delphi anketinden sonra, SPIRIT grubunun 16 üyesi (bu yazının yazarları olarak adlandırılmışlardır) Aralık 2007'de Kanada, Ontario, Ottowa'da ve 14 üyesi de Eylül 2009' da Kanada, Ontario, Toronto'da, anket sonuçlarını gözden geçirmek, çatışmalı maddeleri tartışmak ve taslak kontrol listesini rafine etmek üzere toplanmıştır. Her toplantıdan sonra, gözden geçirilmiş kontrol listesi ilave geribildirim için SPIRIT grup üyeleri arasında yeniden dolaştırılmıştır.

Ikinci bir sistematik derleme belirli protokol maddelerinin deneyin yürütülmesi ya da yanlılık riski ile ilgililiği yönünden deneysel kanıtları tanımlamıştır. Bu derlemenin sonuçları SPIRIT kontrol listesindeki maddelerin dahil edilmesi ya da dışlanmasına karar vermede bilgi sağlamıştır. Bu derleme aynı zamanda SPIRIT 2013'ün kanıt dayanağını da oluşturmuştur ${ }^{31}$. Bazı maddeler küçük ya da hiç saptanamayan deneysel kanıta sahip olması (örneğin, başlık), ve bazı maddeler ise güçlü bir pragmatik ya da etik gerekçeye dayanarak kontrol listesine dahil edilmiştir.

Son olarak, taslak kontrol listesinin pilot testini yüksek lisans düzeyinde verilen klinik araştırma yöntemleri metot dersi kapsamında deney protokolü geliştirmek için bu dökümanı kullanan Toronto Üniversitesi öğrencileri ile 2010 ve 2011 yıllarında gerçekleştirdik. Kontrol listesinin içeriği, biçimi ve yararlılığı hakkındaki geri bildirimler isimsiz bir anket aracılığıyla elde edilmiş ve son SPIRIT kontrol listesine dahil edilmiştir.

\section{Klinik Deney Protokolünün Tanımı}

Her çalışma bir protokolü gerektirse de protokolün net tanımı araştırmacılar, sponsorlar ve diğer paydaşlar arasında çeşitlilik gösterir. SPIRIT girişimi için protokol, deneyin arka planı, gerekçeleri, amaçları, çalışma grubu, girişimleri, yöntemleri, istatistiksel analizleri, etik konuları, yaygınlaştırma planı ve yönetimi; deney yöntemleri ve yürütülmesinin anahtar yönlerinin tekrar edilebilirliği; ve etik onaydan sonuçların yayımlanmasına kadar deneyin bilimsel ve etik sağlamlıkla uygulanmasının anlaşılmasına yönelik yeterli ayrıntıyı sağlayan bir doküman olarak tanımlanır. 
Protokol bir maddeler listesinden daha fazlasıdır. Deneyin unsurlarının tam olarak anlaşılmasına yönelik uygun çerçeve ve anlatım sağlayan bütünleştirici bir belge olması gerekir. Örneğin, karmaşık bir müdahalenin tanımının, uygun uzmanlığa sahip kişiler tarafından kopyalanmasını sağlamak için eğitim materyalleri ve rakamları içermesi gerekebilir.

Tam protokolün kurumsal hakem kurulu ya da etik komite tarafından onaylanması için kaydedilmesi gerekir ${ }^{34}$. Deney araştırmacıları ya da sponsorlara kaydetmeden önce protokollerinde SPIRIT kontrol listesi maddelerini belirtmeleri önerilmektedir. Belirli maddelerdeki ayrıntılar henüz sonuçlandırılmadıysa, o zaman da bunun protokolde belirtilmesi ve geliştikçe maddelerin güncellenmesi gerekir. Protokol genellikle deney sırasında değiştirilen "yaşayan" bir dökümandır. Deneyin tasarımı ve yürütülmesindeki önemli değişikliklerin tarihleriyle birlikte şeffaf bir denetim izinin oluşturulması bilimsel kayıt tutmanın gerekli parçasıdır. Deney araştırmacılarının ve sponsorların kurumsal hakem kurulu tarafindan onaylanan protokole uymaları ve en son protokol versiyonunda yapılan düzeltmeleri belgelemeleri beklenir. Önemli protokol düzeltmeleri ortaya çıktığında kurumsal hakem kuruluna ve deney kayıt platformuna rapor edilmesi ve ardından deney raporunda belirtilmesi gereklidir.

\begin{tabular}{|c|c|c|c|c|c|c|c|c|}
\hline & \multicolumn{8}{|c|}{ Çalışma Evreleri } \\
\hline & Kayit & Atama & & sonras & & & & Bitiriş \\
\hline Zaman noktası* & $-\mathrm{t} 1$ & 0 & t1 & t2 & t3 & t4 & vs. & tx \\
\hline Kayit & & & & & & & & \\
\hline $\begin{array}{l}\text { Uygunluk } \\
\text { taraması }\end{array}$ & $\mathrm{x}$ & & & & & & & \\
\hline $\begin{array}{l}\text { Bilgilendirilmiş } \\
\text { onam }\end{array}$ & $\mathrm{x}$ & & & & & & & \\
\hline $\begin{array}{l}\text { (Diğer işlemlerin } \\
\text { listesi) }\end{array}$ & $x$ & & & & & & & \\
\hline Atama & & $\mathrm{x}$ & & & & & & \\
\hline Girişimler: & & & & & & & & \\
\hline (Girişim A) & & & & & & & & - \\
\hline (Girişim B) & & & $\mathrm{x}$ & & $\mathrm{x}$ & & & \\
\hline $\begin{array}{l}\text { (Diğer çalışma } \\
\text { gruplarının listesi) }\end{array}$ & & & & & & & & - \\
\hline Değerlendirmeler: & & & & & & & & \\
\hline $\begin{array}{l}\text { (Temel } \\
\text { değiskkenlerin } \\
\text { listesi) }\end{array}$ & $\mathrm{x}$ & $x$ & & & & & & \\
\hline (Çııtılıarın listesi) & & & & $x$ & & $x$ & vs. & $x$ \\
\hline $\begin{array}{l}\text { (Diğer veri } \\
\text { değiskenlerinin } \\
\text { listesi) }\end{array}$ & & & $x$ & $\mathrm{x}$ & $\mathrm{x}$ & $\mathrm{x}$ & vs. & $\mathrm{x}$ \\
\hline
\end{tabular}

Önerilen içerik değişik şematik şekillerde yerleştirilebilir. Örnekler için, bakınız SPIRIT 2013 Açıklama ve Ayrıntılandırma ${ }^{31}$. Bu şablon SPIRIT gruptan kopyalanarak SPIRIT' in izniyle yeniden üretilmiştir. SPIRIT = Standard Protocol Items: Recommendation for Interventional Trials.

*Bu satıra özgün zaman noktalarını listeleyiniz.

Şekli 1. Kaydetme, Girişimler ve Değerlendirmelerin Programlanması İçin Önerilen Örnek Şablon
SPIRIT 2013 Bildirisi

SPIRIT 2013 Statement

\section{SPIRIT 2013’ ün Kapsamı}

SPIRIT 2013 bildirisi, ekleri dahil olmak üzere bir klinik deney protokolünün içeriğini uygular. Klinik deney, insan katılımcılara, sağlıkla ilişkili çıktılar üzerindeki etkisini değerlendirmek amacıyla bir ya da daha fazla girişimin uygulandığı ileriye doğru bir çalışmadır. SPIRIT 2013'ün birincil kapsamı randomize deneylerle ilgilidir, ancak aynı konular büyük ölçüde çalışma tasarımı, girişim ya da konu fark etmeksizin tüm klinik deney türleri için geçerlidir.

SPIRIT 2013 bildirisi asgari protokol içeriği konusunda rehberlik sağlar. Belirli durumlar ilave protokol maddelerini gerekli hale getirebilir. Örneğin, bir faktöriyel çalışma tasarımı özel gerekçelendirme gerektirebilir; çapraz tasarımlı deneyler, taşıma etkileri gibi benzersiz istatistiksel değerlendirmelere sahiptir; sanayi sponsorlu deneylerin ilave düzenleme gereklilikleri olabilir.

Protokol ve ekleri genellikle SPIRIT kontrol listesinin her maddesi ile ilgili ayrıntılı bilginin tek arşividir. Var olan deney protokollerini kullanarak, biz her bir maddenin model örneğini tanımlayabildik ${ }^{31}$ ki bu durum bir protokol belgesindeki tüm kontrol listesi maddelerinin uygulanabilme kolaylığını gösterir. Bazı deneyler için, istatistik analiz planları, vaka kayıt formları, operasyon kılavuzları ya da araştırmacı sözleşmeleri gibi ${ }^{35,36}$ ayrıntılar ilave dökümanlarda görülebilir. Bu durumlarda; protokol, temel ilkeleri ana hatlarıyla belirlemeli ve varlıklarının bilinmesi için ayrı belgelere atıfta bulunmalıdır.

SPIRIT 2013 bildirisi, genellikle yerel kurallar, gelenekler ya da standart işletim süreçleri gibi şekilsel özelliklerden ziyade öncelikle protokolün içeriği ile ilgilidir. Bununla birlikte, bir içindekiler çizelgesi, bölüm başıkları, kısaltmalar listesi, kaynaklar listesi ve kayıt, girişimler ve değerlendirmelerin şematik tanımı gibi belirli biçimsel geleneklere uymak protokolün gözden geçirilmesini kolaylaştıracaktır (Şekil 1).

Son olarak, SPIRIT 2013'ün amacı, bir deneyin nasıl tasarlanacağı ya da yürütüleceği konusunda bir reçete vermek değil şeffaflığı ve planlananların tam olarak tanımlamasını teşvik etmektir. Kontrol listesi, araştırmanın kalitesini değerlendirmek için kullanılmamalıdır, çünkü kötü tasarlanmış bir araştırmanın protokolü, yetersiz tasarım özelliklerini tam olarak açıklayarak tüm kontrol listesi maddelerini ele alabilir. Bununla birlikte, SPIRIT 2013'ün kullanılması araştırmacılara planlama aşamasında dikkate alınması gereken önemli konuları hatırlatarak deneyin geçerliğini ve başarısını geliştirebilir.

\section{Mevcut Klinik Deney Rehberleri Ile iliş̧isi}

Sistematik geliştirme süreci, uluslararası paydaşlardan görüş alınması ve ilgili deneysel kanıtlara atıfta bulunan açıklayıcı makalesi31 ile SPIRIT 2013 klinik araştırma protokollerine uygulanabilen diğer uluslararası kılavuzlara dayanmaktadır. SPIRIT 2013, 2008 Helsinki Deklerasyonu' nda zorunlu tutulan, protokolün özellikle hitap etmesi gereken çıkar çatışması gibi özgün etik unsurlar olmak üzere tüm etik ilkelere bağlı kalmıştır ${ }^{34}$. 
Tablo 1. SPIRIT 2013 Kontrol Listesi: Klinik Deneme Protokolü için Tavsiye Edilen Maddeler ve ilgili Dokümanlar

\begin{tabular}{|c|c|c|}
\hline Bölüm / Madde & \multicolumn{2}{|c|}{\begin{tabular}{|l|l|} 
Madde Numarası Açıllama \\
\end{tabular}} \\
\hline \multicolumn{3}{|r|}{ Yönetimsel Bilgi } \\
\hline Başlık & 1 & Çalışmanın tasarımı, popülasyonu, müdahale ve eğer var ise deneme kısaltmasını karşılayan açıklayıcı başıık \\
\hline \multirow[t]{2}{*}{ Deney Kaydı } & $2 a$ & Deney kimliği ve kayıt ismi. Henüz kayıt olmamış ise planlanan kayıt ismi. \\
\hline & $2 \mathrm{~b}$ & Dünya Sağlık Örgütü Deney Kayıt Veri Setinin Tüm Maddeleri (Ek Çizelge, www.annal.org erişilebilir) \\
\hline Protokol kopyası & 3 & Tarih ve kopya kimliği \\
\hline Fon & 4 & Finansal malzeme ve diğer desteklerin kaynakları ve tipleri \\
\hline \multirow[t]{4}{*}{ Roller ve Sorumluluklar } & $5 a$ & Protokole katkıda bulunanların isimleri ve bağlı bulunduğu birimler \\
\hline & $5 b$ & Deney sponsorlarının isim ve iletişim bilgisi \\
\hline & $5 c$ & $\begin{array}{l}\text { Çalışma sponsorları ve fonlayıcılarının, bu aktivitelerin her hangi biri üzerinde önemli etkisi olan otoriteler olup olmadığını içerecek } \\
\text { şekilde, varsa, çalışmanın tasarımı, verilerin toplanması, yönetimi, analizi ve yorumlanması; rapor yazımı; ve raporun yayın için } \\
\text { kaydedilmesi kararındaki rolleri }\end{array}$ \\
\hline & $5 \mathrm{~d}$ & $\begin{array}{l}\text { Yapı, roller, ve uygunsa, koordinasyon merkezi, yönlendirici komite, dönüm noktası karar komitesi, veri yönetim ekibi, ve deneye eşlik } \\
\text { eden diğer birey ve grupların sorumlulukları (Veri İzleme Komitesi -Vik -için bakınız madde 21a) }\end{array}$ \\
\hline \multicolumn{3}{|l|}{ Giriş } \\
\hline \multirow[t]{2}{*}{ Temel dayanaklar ve Gerekçe } & $6 a$ & $\begin{array}{l}\text { Araştırma sorusunun tanımlanması ve her bir girişimin yarar ve zararlarını inceleyen ilişkili çalışmaların (yayınlanmış ve yayınlanmamış) } \\
\text { özetlenmesini içerecek şekilde deneyi yapmanın gerekçelendirilmesi }\end{array}$ \\
\hline & $6 b$ & Karşılaştırma seçiminin açıklanması \\
\hline Amaçlar & 7 & Özgün amaçlar ya da hipotezler \\
\hline Deney Tasarımı & 8 & $\begin{array}{l}\text { Araştırma türünü ( paralel grup, çapraz, faktoriyel, tek grup vs.), atama oranı ve çerçevesini (üstünlük, eşitlik, daha kötü olmama, } \\
\text { açıklayıcı) içerecek şekilde deney tasarımının tanımlanması }\end{array}$ \\
\hline \multicolumn{3}{|l|}{ Yöntemler } \\
\hline \multicolumn{3}{|l|}{ Katılımcılar, girişimler ve çıktılar } \\
\hline Çalışma yeri & 9 & $\begin{array}{l}\text { Çalışma yerlerinin (Toplum, klinik, akademik hastane vs.) ve verinin toplanacağı ülkelerin listesinin tanımlanması. Çalışma alanları } \\
\text { listesinin nereden elde edileceğine atıfta bulunma }\end{array}$ \\
\hline Seçim ölçütleri & 10 & $\begin{array}{l}\text { Katılımcılar için dahil edilme ve dışlanma ölçütleri. Uygunsa, çalışma merkezleri ve girişimleri gerçekleştiren bireylerin (cerrah, } \\
\text { psikoterapist vs.) seçim ölçütleri }\end{array}$ \\
\hline \multirow[t]{4}{*}{ Girişimler } & $11 \mathrm{a}$ & Nasıl ve ne zaman gerçekleştirileceğini içerecek şekilde, tekrar edilebilirlik için yeterli olacak ayrıntılarla, her bir grup için girişimler \\
\hline & $11 \mathrm{~b}$ & $\begin{array}{l}\text { Atanan girişimlerin belirtilen deney katııımcılarında sürdürülmemesi ya da değiştirilmesi için ölçütler (zararlı etkiye, katılımcının isteğine } \\
\text { ya da hastalığın gelişmesi/kötüleşmesine cevaben ilaç dozu değişikliği) }\end{array}$ \\
\hline & $11 \mathrm{c}$ & Uyumu izlemek için girişim protokolüne ve her hangi bir işleme uymayı geliştirme stratejileri (ilaç tablet iadesi, laboratuar testleri vs.) \\
\hline & $11 \mathrm{~d}$ & Deney sırasında izin verilen ya da yasaklanan ilişkili eşzamanlı bakım ve girişimler \\
\hline Çıktılar & 12 & $\begin{array}{l}\text { Özgün ölçüm değişkenleri (sistolik kan basıncı vs.), analiz ölçüsü (temel ölçüume göre değişim, son değer, zaman içinde değişim vs.), } \\
\text { ortalama yöntemini (medyan, oran vs.) içerecek şekilde birincil, ikincil ve diğer çıktıların ve her bir çıktı için ölçüm zamanının belirtilmesi. }\end{array}$ \\
\hline
\end{tabular}


Tablo 1. SPIRIT 2013 Kontrol Listesi: Klinik Deneme Protokolü için Tavsiye Edilen Maddeler ve ilgili Dokümanlar (devamı)

\begin{tabular}{|c|c|c|}
\hline Katılımcı zaman çizelgesi & 13 & Deneyin kaydı, girişim, değerlendirme ve katılımcı ziyaretlerine ait zaman çizelgesi Şematik bir akış çizelgesi oldukça önerilir (Şekil 1). \\
\hline Örnek Büyüklüğü & 14 & $\begin{array}{l}\text { Her hangi bir örnek büyüklüğü hesaplamasını destekleyen klinik ve istatistiksel varsayımları içerecek şekilde, çalışma amaçlarına ulaşmak } \\
\text { için tahmini katılımcı sayısı ve nasıl saptandığı. }\end{array}$ \\
\hline Katılımcıların belirlenmesi & 15 & Hedef örnek büyüklüğü için yeterli katılımcı kaydına erişmeye yönelik stratejiler \\
\hline \multicolumn{3}{|c|}{\begin{tabular}{|l|} 
Girişimlerin atanması (kontrollü deneyler \\
için)
\end{tabular}} \\
\hline Atama dizisi oluşturma & $16 a$ & $\begin{array}{l}\text { Atama dizisi oluşturma yöntemi (bilgisayarda oluşturulmuş rastgele sayılar vs.), ve tabakalama için her hangi bir faktörün listesi. Rastgele } \\
\text { dizilimin tespit edilebilirliğini azaltmak için, planlı herhangi bir kısıllamanın (bloklama vs.) detaylarının katılımcıları kaydeden ve girişimleri } \\
\text { gerçekleştirenlerin elde edemeyeceği ayrı bir doküman olarak sağlanması gerekir. }\end{array}$ \\
\hline Atama Gizleme mekanizması & $16 \mathrm{~b}$ & $\begin{array}{l}\text { Atama dizisini hayata geçirme mekanizması (merkezi telefon, sırasıyla numaralanmış opak mühürlü zarflar vs.), girişimlere ayrılana kadar } \\
\text { dizilimin gizlenmesine yönelik her bir adımı tanımlama }\end{array}$ \\
\hline Uygulama & $16 \mathrm{c}$ & Atama dizisini kim oluşturacak, katılımcıları kim kaydedecek ve katılımcıları girişimlere kim atayacak \\
\hline \multirow[t]{2}{*}{ Körleme (maskeleme) } & $17 a$ & Girişimlere atama sonrası kim körlenecek (deney katılımcıları, bakım vericiler, çıktıları değerlendirenler, veri analizcileri), ve nasıl \\
\hline & $17 \mathrm{~b}$ & $\begin{array}{l}\text { Körlendiyse, körlenmemeye hangi koşullarda izin verilebileceği ve deney sırasında bir katııımcının atandığı girişimi açıklamada usulun ne } \\
\text { olacağı belirlenmeli }\end{array}$ \\
\hline \multicolumn{3}{|l|}{ Veri toplama yönetimi, ve analizi } \\
\hline \multirow[t]{2}{*}{ Veri toplama metotları } & $18 \mathrm{a}$ & $\begin{array}{l}\text { Veri kalitesini arttırmayla ilgili (ölçüm tekrarları, değerlendiricilerin eğitimi vs.) süreçleri ve güvenirlik ve geçerlikleri eklenerek çalışma } \\
\text { araçlarının tanımlamasını da ( anketler, laboratuar testleri vs.) içerecek şekilde çıktı, temel ve diğer deney verilerinin değerlendirilmesi ve } \\
\text { toplanması için planlamalar. Eğer protokolde yer almıyorsa, biliniyorsa, veri toplama formlarının bulunabileceği yere atıfta bulunma. }\end{array}$ \\
\hline & $18 \mathrm{~b}$ & $\begin{array}{l}\text { Müdahale protokollerini bırakan ya da bunlardan sapan katılımcılar için toplanacak sonuç verilerinin listesi dahil olmak üzere, katılımcıyı } \\
\text { elde tutma ve tam takibi teşvik etme planları }\end{array}$ \\
\hline Veri yönetimi & 19 & $\begin{array}{l}\text { Veri kalitesini arttırmayla ilgili her hangi bir süreci (iki kez veri girişi, veri değerleri için aralık kontrolü vs.) içerecek şekilde veri girişi, } \\
\text { kodlama, güvenlik ve depolama için planlamalar. Protokolde yer almıyorsa, veri yönetimi sürecinin nerede bulunabileceğine atıfta } \\
\text { bulunma. }\end{array}$ \\
\hline \multirow[t]{3}{*}{ İstatistiksel metodlar } & $20 a$ & $\begin{array}{l}\text { Birincil ve ikincil çıktıların analizi için istatistik yöntemler. Protokolde yer almıyorsa, istatistik analiz planlarının nerede bulunabileceğine } \\
\text { atıfta bulunma. }\end{array}$ \\
\hline & $20 \mathrm{~b}$ & Herhangi bir ilave analiz yöntemi (altgrup ve düzeltilmiş analizler) \\
\hline & $20 c$ & $\begin{array}{l}\text { Protokole uyumsuzlukla ilişkili grubun analizlerinin tanımı (randomize edildiği şekilde analiz vs.), ve eksik verilerin ele alınmasında } \\
\text { herhangi bir istatistik yöntem (çoklu tamamlama vs.) }\end{array}$ \\
\hline \multicolumn{3}{|l|}{ Gözetim } \\
\hline \multirow[t]{2}{*}{ Veri Gözetimi } & $21 a$ & $\begin{array}{l}\text { Vik' in yapısı; rolleri ve raporlama yapılanmasının özeti; sponsorlar ve çıkar çatışmasından bağımsız olup olmadığının bildirilmesi; ve } \\
\text { protokolde yer almıyorsa, sözleşmenin ileri ayrıntılarının nerede bulunabileceğine atıfta bulunma. Alternatif olarak, vik'e neden gerek } \\
\text { olmadığının açıklaması. }\end{array}$ \\
\hline & $21 b$ & $\begin{array}{l}\text { Herhangi bir ara analiz ve durdurma rehberinin bu ara sonuçlara kimin ulaşabileceği ve deneyin sonlandırılmasına son kararı kimin } \\
\text { vereceğini içerecek şekilde tanımlanması }\end{array}$ \\
\hline
\end{tabular}


Tablo 1. SPIRIT 2013 Kontrol Listesi: Klinik Deneme Protokolü için Tavsiye Edilen Maddeler ve İgili Dokümanlar (devamı)

\begin{tabular}{|c|c|c|}
\hline Zararlar & 22 & $\begin{array}{l}\text { Toplanan ya da spontan olarak bildirilen ters etkilerin ve diğer deneysel girişim ve deneyin yürütümünün kasıtsız etkilerinin toplanması, } \\
\text { değerlendirilmesi, raporlanması ve yönetimine ilişkin planlama }\end{array}$ \\
\hline Denetim & 23 & Varsa, deney yürütümünün denetimi için denetim sıklığı ve işlemler ve sürecin araştırmacılar ve sponsorlardan bağımsız olup olmadığı \\
\hline \multicolumn{3}{|l|}{ Etik ve yayın } \\
\hline Araştırma etik onayı & 24 & Araştırma Etik Komitesi/Kurumsal Hakem Kurulu başvuru planları \\
\hline Protokol değişiklikleri & 25 & $\begin{array}{l}\text { ilgili taraflarla (araştırmacılar, Araştırma Etik Komitesi/Kurumsal Hakem Kurulu, araştırma katılımcıları, deney kayıt birimi, dergiler, kural } \\
\text { koyucular vs.) önemli protokol düzeltmeleri (seçim ölçütleri, çıktılar, analizlerde değişim vs.) için iletişimi planlama }\end{array}$ \\
\hline \multirow[t]{2}{*}{ Onam ya da rıza } & $26 a$ & Olası deney katııımcıları ya da yetkilendirilmiş vekillerinden kim bilgilendirilmiş onam alacak ve nasıl (bakınız madde 32) \\
\hline & $26 \mathrm{~b}$ & Uygunsa, katılımcıların verileri ve biyolojik örneklerinin toplanması ve kullanımı için ilave onam gerekleri \\
\hline Gizlilik & 27 & $\begin{array}{l}\text { Deney öncesinde, sırasında ve sonrasında gizliliği koruyabilmek için olası ve kaydedilen katılımcıların bireysel bilgileri nasıl toplanacak, } \\
\text { paylaşılacak ve sürekliliği nasıl sağlanacak }\end{array}$ \\
\hline Menfaat bildirimi & 28 & Tüm deney ve çalışma yeri için birincil araştırmacılar yönünden finansal ve diğer çıkar çatışmaları \\
\hline Veriye Erişim & 29 & Son deney verilerine kimin erişeceği ve araştırmacılar için bu erişimi sınırlandıran anlaşmaların bildirimi \\
\hline Yardımcı ve deney sonrası bakım & 30 & Varsa, yardımcı ve deney sonrası bakım ve deney katılımcılarından zarar görenler için kompanze güvenceleri, \\
\hline \multirow[t]{3}{*}{ Yaygılaştırma politikası } & $31 a$ & $\begin{array}{l}\text { Herhangi bir yayın sınırlamasını da içerecek şekilde katılımcılar, sağlık bakım profesyonelleri, toplum ve diğer ilgili gruplara (yayın yoluyla, } \\
\text { sonuç veri tabanında raporlama, ya da diğer veri paylaşma düzenlemeleri vs.) deney sonuçlarının nasıl iletileceğine ilişkin araştırmacı ve } \\
\text { sponsorlar için planlamalar }\end{array}$ \\
\hline & $31 \mathrm{~b}$ & Yazarlık seçim rehberleri ve her hangi bir profesyonel yazar kullanma düşüncesi \\
\hline & $31 \mathrm{c}$ & Varsa, tam protokole, bireysel düzeyde veri setine, ve istatistik koda toplumsal erişim izni verme planlamaları \\
\hline \multicolumn{3}{|l|}{ Ekler } \\
\hline Bilgilendirilmiş onay metaryelleri & 32 & Katıtımcılar ve yetkilendirilmiş vasilere verilen onam formu ve diğer dökümanın örneği \\
\hline Biyolojik türler & 33 & $\begin{array}{l}\text { Mevcut deneyde ve uygunsa, gelecekteki yardımcı çalışmalardaki genetik ya da moleküler analiz için biyolojik örneklerin toplanması, } \\
\text { laboratuar incelemesi ve saklanması planlamaları }\end{array}$ \\
\hline
\end{tabular}


Tablo 2. Olası Yararlar ve SPIRIT 2013' e Uyumu Desteklemek İçin Önerilen Paydaş Eylemleri

\begin{tabular}{|c|c|c|}
\hline Paydaş & Önerilen Eylemler & Potansiyel Yararlar \\
\hline \multirow[t]{3}{*}{ Klinik deney grupları, araştırmacılar, sponsorlar } & SPIRIT'in standart rehber olarak uyarlanmasI & Protokol içeriğinde kalite, tamlık ve tutarlııkta gelişme \\
\hline & Protokol yazımında araç olarak kullanma. & \begin{tabular}{|l|} 
Ana protokol maddeleri için gerekçeleri ve göz önünde bulundurulacak \\
konuların anlaşılırlığını geliştirme
\end{tabular} \\
\hline & & Protokolün gözden geçirilme etkililiğinde artma \\
\hline \multirow[t]{2}{*}{$\begin{array}{l}\text { Araştırma etik komiteleri/kurumsal hakem } \\
\text { kuruluşları, fonlama daireleri, kural koyucu daireler }\end{array}$} & $\begin{array}{l}\text { Kaydedilmiş protokoller için SPIRIT’e uymanın zorunlu tutulması ya da } \\
\text { teşvik edilmesi }\end{array}$ & Protokol kaydının kalitesi, tamlığı ve tutarlıı̆̆ında gelişme \\
\hline & Eğitim aracı olarak kullanma & $\begin{array}{l}\text { Protokol gereklilikleri konusunda gözden geçirmenin etkinliği ve } \\
\text { sorgulamaların azalmasında artış }\end{array}$ \\
\hline Eğitimciler & SPIRIT kontrol listesi ve açıklayııı makaleyi eğitim aracı olarak kullanma & $\begin{array}{l}\text { Anahtar protokol maddelerinin gerekçeleri ve göz önünde } \\
\text { bulundurulacak konuların anlaşlırlığında gelişme }\end{array}$ \\
\hline Hastalar, deney katılımcıları ve politika yapıcılar & $\begin{array}{l}\text { SPIRIT'in deney araştırmacıları ve sponsorlar tarafından kullanımını } \\
\text { savunma }\end{array}$ & $\begin{array}{l}\text { Protokol içeriğinde şeffaflık, hesap verebilirlik, eleştirel değerlendirme } \\
\text { ve gözden kaçmalarla ilgili gelişme }\end{array}$ \\
\hline \multirow[t]{3}{*}{ Deney kayıt birimleri } & SPIRIT'e dayalı protokolleri teşvik etme & Kaydedilmiş raporların kalitesinde artış \\
\hline & Sonuçların açıklanmasına eşlik edecek tam protokolün kaydedilmesi & $\begin{array}{l}\text { SPIRIT kontrol listesi madde } 2 \mathrm{~b} \text { ( Kayıt birimi Veri Seti) güncellendiğinde } \\
\text { deneyi uygulayanlardan kayıt raporlarını güncellemeyi geliştirme }\end{array}$ \\
\hline & & $\begin{array}{l}\text { Tam protokol ve sonuçlarına ev sahipliği yapan kayıt birimleri için } \\
\text { protokol içeriğinde kalite, tamlık ve tutarlııkta gelişme }\end{array}$ \\
\hline \multirow[t]{3}{*}{ Dergi editörleri ve yayıncılar } & $\begin{array}{l}\text { SPIRIT'in yayınlanmış ve yayınlanmamış protokoller için standart rehber } \\
\text { olarak onaylanması }\end{array}$ & Protokol içeriğinin kalite, tamlık ve tutarlılı̆̆ında gelişme \\
\hline & Yazarlar için yönergede SPIRIT' e atıfı ekleme & \begin{tabular}{|l|} 
Protokole uyma ve seçici raporlamayı değerlendirmede kullanılabilecek \\
gelişmiş protokol içeriğiyle deney makalelerinin hakemliğini geliştirme
\end{tabular} \\
\hline & $\begin{array}{l}\text { Protokolün makaleyle beraber kaydedilmesini talep etme, hakemler } \\
\text { arasında dolaştırma ve yazarları web eklentisi olarak ulaşılabilir olması için } \\
\text { teşvik etme }\end{array}$ & Deneyin okuyucular tarafından şeffaflığı ve yorumlamasını geliştirme \\
\hline
\end{tabular}

SPIRIT = Standard Protocol Items: Recommendation for Interventional Trials-Standart Protokol Maddeleri: Girişimsel Deneyler için Öneriler 
Ek olarak, SPIRIT 2013, verileri düzenleyici otoritelere kaydedilecek olan klinik deneyler için 1996' da yazılmış olan Uluslararası Uyumlu İyi Klinik Uygulamalar Konferansı E6 Rehberi tarafından önerilen protokol maddelerini kapsamaktadır ${ }^{37}$. SPIRIT bildirisi belirli anahtar protokol maddelerinde (örneğin, atamanın gizlenmesi, deneyin kaydı ve onam süreci) ilave öneriler sunarak Iyi Klinik Uygulamalar rehberine dayanır. SPIRIT' in aksine, Iyi Klinik Uygulama Rehberi informal uzlaşı yöntemlerini kullanmıştır, açık olmayan katkı sağlayıcılara sahiptir ve deneysel kanıtlarla desteklenen atıflardan yoksundur ${ }^{38}$. SPIRIT 2013 bildirisi aynı zamanda Dünya Sağlık Örgütü39, Uluslararası Tıbbi Dergi Editörleri Komitesi" ${ }^{40}$, ClinicalTrials.gov'a özgü mevzuat ${ }^{41}$, Avrupa Komisyonu ${ }^{42}$ ve diğerlerinin deney kayıt gerekliliklerini de desteklemektedir. Örneğin, SPIRIT kontrol listesinin 2b maddesi Dünya Sağıık Örgütü Deney kaydı veri setinin protokol listesini ( Ek Çizelge; www.annal.org'dan erişilebilir) önermektedir ki bu Uluslararası Tıbbi Dergi Editörleri Komitesi'nin deney kaydı için zorunlu tuttuğu asgari bilgi miktarıdır. Bu veri setinin SPIRIT protokol bölümünde olması sadece bir tür deney özeti biçimi olarak hizmet etmez aynı zamanda kayıt girişlerindeki bilgi kalitesini arttırmaya yardımcı olmayı amaçlamaktadır. Kayıta özgü veri, protokol bölümünden kolaylıkla saptanarak kayıt alanına kopyalanabilir. İlaveten, bu bölüme uygulanan protokol düzeltmeleri kayıtlı verileri güncellemek için araştırmacıları uyarabilir.

SPIRIT 2013 bildirisi CONSORT 2010'dan (Consolitaded Standarts of Reporting Trials) ${ }^{43}$ uygulanabilir maddeleri yansıtır. Her iki kontrol listesinde de ortak ifadeler için kullanılan tutarlı ifadelendirme ve yapı SPIRIT'e dayalı protokolden CONSORT'a dayalı son rapora geçişi kolaylaştıracaktır. SPIRIT grubu aynı zamanda şeffaflığı ve yüksek kaliteli protokol içeriğini geliştirmeye yönelik uluslararası çabalara destek vermek için deney kayıt kuruluşları, Klinik Veri Değişim Standartları Birliği Protokol Temsil Grubu ve Sağlık Hizmetlerinde Pragmatik Kontrollü Deneyler gibi protokol standartları ile ilişkili diğer girişim liderleri ile de bağlantılıdır.

\section{Olası Etki}

Geniş paydaş yelpazesi SPIRIT 2013 bildirisinin ve açıklayıCı makalesinin yaygınlaştırılmasında yararlı olabilir (Tablo 2). Pilot-test ve informal geri bildirimler araştırma protokol taslaklarını oluşturduğunda özellikle deneysel araştırmacılar için yararlı olduğunu göstermektedir. Aynı zamanda yeni araştırmacılar, akran değerlendiriciler ve kurumsal hakem kurul üyeleri için bir bilgi kaynağı olarak hizmet edebilmektedir.

Aynı zamanda deneyin hayata geçirilmesinde de yarar olasılığı vardır. Klinik deneylerde protokolün geliştirilmesinden etik onayın alınması ve katılımcı kaydına başlanmasına kadar olan sürenin aşırı ertelenmesi halen önemli bir endişe kaynağı olmaya devam etmektedir ${ }^{44}$. Protokollerin tamlığının geliştirilmesi, tamamlanmamış ve açık olmayan bilgiler konusunda araştırmacılara yönelik kaçınılabilir sorgulamaları azaltarak protokol incelemesinin verimliliğini artırmaya yardımcı olabilir. Deney başlamadan önce anahtar bilgilerin tam olarak belgelenmesi ve önemli
SPIRIT 2013 Bildirisi

SPIRIT 2013 Statement

konulardaki farkındalığın artmasıyla birlikte, SPIRIT'in kullanımı tekrarlayan protokol düzeltmelerinin sayısı ve yükünü azaltmaya yardım edebilir ki bunların çoğundan dikkatli bir protokol taslağı ve geliştirilmesi ile kaçınılabilir ${ }^{15}$. SPIRIT 2013'ün Kurumsal Hakem Kurulları, finansman kuruluşları, düzenleyici kuruluşlar ve dergiler tarafından tek bir standart olarak yaygın bir şekilde benimsenmesi, SPIRIT'e dayalı tek bir protokolle çok çeşitli paydaşların ortak uygulama gerekliliklerini yerine getirecek olan deney araştırmacıları ve sponsorların işini kolaylaştırmıştır. Daha iyi protokoller, araştırma uygulayıcılarının deneyi protokol yazarlarının amaçladığı gibi uygulamasına yardım eder.

Dahası, SPIRIT 2013'e bağlılık protokollerin, eleştirel değerlendirme ve deney yorumu için gereken bilgileri içermesini sağlamaya da yardım eder. Yüksek kaliteli protokoller deneyin yöntemi ve yürütülmesi konusunda dergilerden ya da deney kayıtlarından elde edilemeyecek önemli bilgiler sunabilir ${ }^{45-57}$. Araştırmacıların özgün niyetlerinin şeffaf bir kaydı olarak protokolün deney sonuç raporu ile karşılaştırılması birincil çıktılarda değiştirme yapmak gibi ${ }^{19,49}$ sonuçların seçici raporlanması ve bildirilmemiş düzeltmeleri saptamaya yardım edebilir ${ }^{48}$. Ancak, klinik deney protokolleri genellikle toplumca erişilebilir değildir ${ }^{45}$. SPIRIT 2013 bildirisi deneyin geçerliği ve uygulanabilirliğinin tam değerlendirilmesini kolaylaştırmak için protokoller, toplumca erişilebilir olduğunda daha büyük bir etkiye sahip olacaktır $11,12,14,50$.

SPIRIT 2013 rehberinin maksimum etkisini (Tablo 2) yakalayabilmesi için, CONSORT ${ }^{51}$ gibi geniş kabul gören raporlama rehberlerinde olduğu gibi anahtar paydaşlar tarafından desteklenmesi gerekir. SPIRIT'i benimseyen kuruluşların isimleri SPIRIT web sitesinde (www.spiritstatement.org) yayınlayacak ve uygulamaya geçirilmesini kolaylaştırmak için kaynak sağlayacağız. SPIRIT önerilerinin geniş kabulü protokolün taslağını, içeriğini ve uygulanmasını geliştirmeye; deneyin kaydedilmesi, etkinliği ve uygulanmasını kolaylaştırmaya ve nihayet hasta bakım yararı için şeffaflığı arttırmaya yardım edebilir.

Orijinal makaleye ait bilgiler:

${ }^{1}$ Women's College Research Institute, Women's College Hospital, and Keenan Research Centre at the Li Ka Shing Knowledge Institute of St. Michael's Hospital, University of Toronto, Toronto, Ontario, Canada; Ottawa Methods Centre, Ottawa Hospital Research Institute, Ethics Office, Canadian Institutes of Health Research, and University of Ottawa,Ottawa, Ontario, Canada; Centre for Statistics in Medicine, University of Oxford, Oxford, United Kingdom; Nordic Cochrane Centre, Rigshospitalet, Copenhagen, Denmark; University of Utah School of Medicine, Salt Lake City, Utah; Center for Clinical Trials, Johns HopkinsBloomberg School of Public Health, Baltimore, Maryland; Janssen Research \& Development, Janssen Pharmaceutical Companies of Johnson \& Johnson, Titusville, New Jersey; UK Medical Research Council Clinical Trials Unit, The Lancet, and BMJ, London, United Kingdom; NCIC Clinical Trials Group, Cancer Research Institute, Queen's University, Kingston, Ontario, Canada; Quantitative Sciences, FHI 360, and GlaxoSmithKline, 
Research Triangle Park, North Carolina; The Dartmouth Institute for Health Policy and Clinical Practice, The Geisel School of Medicine at Dartmouth, Hanover, New Hampshire; The PR Lee Institute for Health Policy Studies, University of California, San Francisco, San Francisco, California.

Feragatname: Dr. Krleža-Jeric'önceden Kanada Sağlık Araştırmaları Enstitütüsünde görevliydi, (Bilgi Çeviri Dalı), ve Dr. Parulekar NCIC Klinik Deneyler Grubuna bağlıdır. Fon sağlayıcılar, projenin tasarımı ve yürütülmesi; verilerin toplanması, yönetimi, analizi ve yorumlanması; ve makalenin hazırlanması, gözden geçirilmesi ve onayına başka türlü girdisi olmazdı. Dr. Berlin Janssen Ilaç Firması of Johnson \& Johnson tarafından işe alınmıştı, Dr. Sox Annals of Internal Medicine' in fahri editörüdür, ve Dr. Rockhold GlaxoSmithKline tarafından işe alınmıştır.

Teşekkür: Yazarlar Drs. Mona Loufty and Patricia Parkin'e SPIRIT kontrol listesinin pilot uygulamasını lisansüstü ders öğrencilerinde yaptığı için teşekkür ederler. Yazarlar ayrıca Dr. Genevie ve Dubois-Flynn'e 2009 SPIRIT toplantısına katılmalarından şükranlarını sunar

Ana Destek: SPIRIT toplantıları için finansal destek Kanada Sağlık Araştırmaları Enstitüsü (grant DET-106068), Kanada Ulusal Kanser Enstitüsü (şimdi Kanada Kanser Derneği Araştırma Enstitüsü), ve Kanada Sağlık illaç ve Teknoloji Dairesi tarafından sağlanmıştır. Kanada Sağlık Araştırma Enstitüsü aynı zamanda devam eden yayma etkinliklerini de desteklemektedir (grant MET-117434).

Çıkar çatışması: Açıklama aşağıdaki linkte görülebilir. www.acponline.org/authors/icmje/ConflictOfInterestForm s.do?msNum_M12-1905.

Tekli baskı izinleri: An-Wen Chan, MD, DPhil, Women's College Research Institute, Women's College Hospital, University of Toronto, 790 Bay Street, Toronto, Ontario M5G 1N8, Canada; e-mail,anwen.chan@utoronto.ca.

Mevcut yazarların adresleri ve yazar katkıları www.annals.org. 'dan sağlanabilir.

Çeviri için;

Etik Kurul Onayı (Kurul adı, tarih ve sayı no): Gerekmemektedir.

Çıkar Çatışması: Çeviren yazarların beyan ettiği bir çıkar çatışması yoktur.

Finansal Destek: Finansal destek sağlanmamıştır.

Katılımcı Onamı: Gerekmemektedir.

Yazar katkıları: Yazarlar çeviride eşit sorumluluk üstlenmiştir.

Teşekkür:

Makaleyi çevirenler, Selçuk Üniversitesi Diş Hekimliğ Fakültesi Öğretim Üyesi Prof. Dr. Sibel Yıldırım'a bu makalenin Türkçe çevrilmesine olanak sağlayan katkısı için teşekkür eder.

Ethics Committee Approval: Not reported.

Conflict of Interest: Not reported.

Funding: None.

Exhibitor Consent: Not reported.

Author contributions: Authors take equal responsibility for the translation.

Acknowledgement: We would like to thank Prof. Dr. Sibel Yıldırım (Faculty member of the Faculty of Dentistry, Selcuk
University) to contribute to the translation of this article into Turkish.

\section{KAYNAKLAR}

1. Rennie D. Trial registration: A great idea switches from ignored to irresistible. JAMA. 2004;292:1359-62.

2. Strengthening the credibility of clinical research [Editorial]. Lancet. 2010;375:1225.

3. Summerskill W, Collingridge D, Frankish H. Protocols, probity, and publication. Lancet. 2009;373:992.

4. Jones $G$, Abbasi $K$. Trial protocols at the BMJ [Editorial]. BMJ. 2004;329:1360.

5. Groves T. Let SPIRIT take you... towards much clearer trial protocols. BMJ Group Blogs. [Internet]. 2009 [Erişim Tarihi September 2009]. Erişim adresi: http://blogs.bmj.com/bmj/2009 /09/25/trish-groveslet-spirit-take-you-towards-much-clearer-trialprotocols/ on 1 October 2012.

6. Altman DG, Furberg CD, Grimshaw JM, Rothwell PM. Lead editorial: trials-using the opportunities of electronic publishing to improve the reporting of randomised trials [Editorial]. Trials. 2006;7:6.

7. Turner EH. A taxpayer-funded clinical trials registry and results database [Editorial]. PLoS Med. 2004;1:e60.

8. Coultas D. Ethical considerations in the interpretation and communication of clinical trial results. Proc Am Thorac Soc. 2007;4:194-8.

9. Siegel JP. Editorial review of protocols for clinical trials [Letter]. N Engl J Med. 1990;323:1355.

10. Murray GD. Research governance must focus on research training. BMJ. 2001;322:1461-2.

11. Chan A-W. Access to clinical trial data [Editorial]. BMJ. 2011;342:d80.

12. Miller JD. Registering clinical trial results: the next step. JAMA. 2010;303:773-4.

13. Krlez`a-Jeric' K, Chan A-W, Dickersin K, Sim I, Grimshaw J, Gluud C. Principles for international registration of protocol information and results from human trials of health related interventions: Ottawa statement (part 1). BMJ. 2005;330:956-8.

14. Lassere $\mathrm{M}$, Johnson $\mathrm{K}$. The power of the protocol. Lancet. 2002;360:1620-2.

15. Getz KA, Zuckerman R, Cropp AB, Hindle AL, Krauss R, Kaitin KI. Measuring the incidence, causes, and repercussions of protocol amendments. Drug Inf J. 2011;45:265-75.

16. Public Citizen Health Research Group v. Food and Drug Administration. 1997; 964:F Supp. 413

17. Tetzlaff JM, Chan A-W, Kitchen J, Sampson M, Tricco A, Moher D. Guidelines for randomized clinical trial protocol content: a systematic review. Syst Rev. 2012;1:43.

18. Chan A-W, Hro'bjartsson A, Haahr MT, Gøtzsche PC, Altman DG. Empirical evidence for selective reporting of outcomes in randomized trials: Comparison of protocols to published articles. JAMA. 2004;291:245765. 
19. Smyth RM, Kirkham JJ, Jacoby A, Altman DG, Gamble C, Williamson PR. Frequency and reasons for outcome reporting bias in clinical trials: Interviews with trialists. BMJ. 2011;342:c7153.

20. Pildal J, Chan A-W, Hro'bjartsson A, Forfang E, Altman DG, Gøtzsche PC. Comparison of descriptions of allocation concealment in trial protocols and the published reports: Cohort study. BMJ. 2005;330:1049.

21. Mhaskar R, Djulbegovic B, Magazin A, Soares HP, Kumar A. Published methodological quality of randomized controlled trials does not reflect the actual quality assessed in protocols. J Clin Epidemiol. 2012;65:602-9.

22. Hro'bjartsson A, Pildal J, Chan A-W, Haahr MT, Altman DG, Gøtzsche PC. Reporting on blinding in trial protocols and corresponding publications was often inadequate but rarely contradictory. J Clin Epidemiol. 2009;62:967-73.

23. Scharf $O$, Colevas $A D$. Adverse event reporting in publications compared with sponsor database for cancer clinical trials. J Clin Oncol. 2006;24:3933-8.

24. Chan A-W, Hro'bjartsson A, Jørgensen KJ, Gøtzsche PC, Altman DG. Discrepancies in sample size calculations and data analyses reported in randomised trials: Comparison of publications with protocols. BMJ. 2008;337: a2299.

25. Al-Marzouki S, Roberts I, Evans S, Marshall T. Selective reporting in clinical trials: Analysis of trial protocols accepted by The Lancet [Letter]. Lancet. 2008;372:201.

26. Herna'ndez AV, Steyerberg EW, Taylor GS, Marmarou A, Habbema JD, Maas Al. Subgroup analysis and covariate adjustment in randomized clinical trials of traumatic brain injury: a systematic review. Neurosurgery. 2005;57:1244- 53.

27. Gøtzsche PC, Hro'bjartsson A, Johansen HK, Haahr MT, Altman DG, Chan A-W. Constraints on publication rights in industry-initiated clinical trials [Letter]. JAMA. 2006;295:1645-6.

28. Gøtzsche PC, Hro'bjartsson A, Johansen HK, Haahr MT, Altman DG, Chan A-W. Ghost authorship in industry-initiated randomised trials. PLoS Med. 2007;4:e19.

29. Lundh A, Krogsbøll LT, Gøtzsche PC. Access to data in industry-sponsored trials [Letter]. Lancet. 2011;378:1995-6.

30. Hopewell S, Dutton S, Yu LM, Chan A-W, Altman DG. The quality of reports of randomised trials in 2000 and 2006: Comparative study of articles indexed in PubMed. BMJ. 2010;340:c723.

31. Chan A-W, Tetzlaff JM, Gøtzsche PC, Altman DG, Mann H, Berlin JA, et al. SPIRIT 2013 explanation and elaboration: guidance for protocols of clinical trials. BMJ. 2013;346:e7586.

32. Moher D, Schulz KF, Simera I, Altman DG. Guidance for developers of health research reporting guidelines. PLoS Med. 2010;7:e1000217.
SPIRIT 2013 Bildirisi

SPIRIT 2013 Statement

33. Tetzlaff JM, Moher D, Chan A-W. Developing a guideline for clinical trial protocol content: Delphi consensus survey. Trials. 2012;13:176.

34. World Medical Association. WMA Declaration of Helsinki-Ethical Principles for Medical Research Involving Human Subjects. [Internet]. 2012 [Erişim Tarihi 1 October 2012]. Erişim adresi: www.wma.net /en/30publications/10policies/b3/index.html on.

35. International Conference on Harmonisation. ICH Harmonised Tripartite Guideline: General Considerations for Clinical Trials: E8. International Conference on Harmonisation of Technical Requirements for Registration of Pharmaceuticals for Human Use. [Internet]. 1997 [Erişim Tarihi 17 July 1997]. Erişim adresi: www.ich.org/fileadmin/Public_ Web_Site/ICH_Products/Guidelines/Efficacy/E8/Step4 /E8_Guideline.pdf

36. International Conference on Harmonisation. ICH Harmonised Tripartite Guideline: Statistical Principles for Clinical Trials: E9. International Conference on Harmonisation of Technical Requirements for Registration of Pharmaceuticals for Human Use. [Internet]. 1997 [Erişim Tarihi 5 February 1998]. Erişim adresi: $\quad$ www.ich.org/fileadmin/Public Web_Site/ICH_Products/Guidelines/Efficacy/E9/Step4 /E9_Guideline.pdf on 1 October 2012.

37. International Conference on Harmonisation. $\mathrm{ICH}$ Harmonised Tripartite Guideline: Guideline for Good Clinical Practice: E6. International Conference on Harmonisation of Technical Requirements for Registration of Pharmaceuticals for Human Use. [Internet]. 1996 [Erişim Tarihi 10 June 1996]. Erişim adresi:www.ich.org/fileadmin/Public_

Web_Site/ICH_Products/Guidelines/Efficacy/E6_R1/St ep4/E6_R1_Guideline.pdf

38. Grimes DA, Hubacher D, Nanda K, Schulz KF, Moher D, Altman DG. The Good Clinical Practice guideline: a bronze standard for clinical research. Lancet. 2005;366:172-4.

39. Sim I, Chan A-W, Gu"Imezoglu AM, Evans T, Pang T. Clinical trial registration: transparency is the watchword. Lancet. 2006;367:1631-3.

40. Laine C, De Angelis C, Delamothe T, Drazen JM, Frizelle $\mathrm{FA}$, Haug $\mathrm{C}$, et al. Clinical trial registration: looking back and moving ahead [Editorial]. Ann Intern Med. 2007;147:275-7.

41. Food and Drug Administration Amendments Act of 2007, HR 2580, 110th Congress, 1st Sess, Title VIII, $\S 801$. Expanded Clinical Trial Registry Data Bank. [Internet]. 2007 [Erişim Tarihi 1 October 2012]. Erişim adresi:

www.govtrack.us/congress/billtext.xpd?billh1103580.

42. European Commission. Communication from the Commission regarding the guideline on the data fields contained in the clinical trials database provided for in Article 11 of Directive 2001/20/EC to be included in the database on medicinal products provided for in Article 57 of Regulation (EC) No 726/2004 (2008/C 
168/02). Official Journal of the European Union. 2008;51:3-4.

43. Schulz KF, Altman DG, Moher D; CONSORT Group. CONSORT 2010 statement: updated guidelines for reporting parallel group randomized trials. Ann Intern Med. 2010;152:726-32.

44. National Research Council. A National Cancer Clinical Trials System for the 21st Century: Reinvigorating the $\mathrm{NCl}$ Cooperative Group Program. Washington, DC: National Academies Pr; 2010.

45. Chan A-W. Out of sight but not out of mind: How to search for unpublished clinical trial evidence. BMJ. 2012;344:d8013.

46. Wieseler B, Kerekes MF, Vervoelgyi V, McGauran N, Kaiser T. Impact of document type on reporting quality of clinical drug trials: A comparison of registry reports, clinical study reports, and journal publications. BMJ. 2012;344: d8141.

47. Reveiz L, Chan A-W, Krleža-Jeric' K, Granados CE, Pinart M, Etxeandia I, et al. Reporting of methodologic information on trial registries for quality assessment: A study of trial records retrieved from the WHO search portal. PLoS One. 2010;5:e12484.

48. Dwan K, Altman DG, Cresswell L, Blundell M, Gamble $\mathrm{CL}$, Williamson PR. Comparison of protocols and registry entries to published reports for randomised controlled trials. Cochrane Database Syst Rev. 2011:MR000031.

49. Dwan K, Altman DG, Arnaiz JA, Bloom J, Chan A-W, Cronin $E$, et al. Systematic review of the empirical evidence of study publication bias and outcome reporting bias. PLoS One. 2008;3:e3081.

50. GlaxoSmithKline. Public disclosure of clinical research. Global Public Policy Issues. [Internet]. 2011 [Erişim Tarihi 1 October 2011]. Erişim adresi: www.gsk.com/policies/GSK-on-disclosure-of -clinicaltrial-information.pdf

51. Turner L, Shamseer L, Altman DG, Schulz KF, Moher D. Does use of the CONSORT Statement impact the completeness of reporting of randomised controlled trials published in medical journals? A Cochrane review. Syst Rev. 2012; 1:60. 